\title{
Evaluation of factors related to labour in women with puerperal sepsis
}

\begin{abstract}
Introduction: Puerperal sepsis is one of the leading causes of preventable maternal mortality and morbidity. Various factors predispose to the infections. The objective of the study was to evaluate factors related to labor in the women with puerperal sepsis. This was an observational study. Study population was all postpartum women with puerperal sepsis admitted in a tertiary care hospital from April 2016- March 2017. The women were carefully evaluated, data collected and analyzed. There were 60 women with puerperal sepsis. Thirty three percent cases were less than 34 weeks gestational age. $81.7 \%$ of the women had institutional deliveries. Fifty three percent women delivered by spontaneous vaginal delivery. Prolonged labor ( $>24$ hours) was present in $73 \%$ of cases. Prolonged rupture of membranes was found in $70 \%$ cases. Grade III and IV sepsis was more in women who had prolonged labour and rupture of membranes $>24$ hours. $(\mathrm{p}<.05)$.
\end{abstract}

Conclusion: Puerperal sepsis was observed more in preterm births and complicated institutional deliveries, while severity was more in women with prolonged labor and prolonged rupture of membrane. Antimicrobial sensitivity should be done of all women with prolonged labor or prolonged rupture of membranes.

Keywords: infections, genital, puerperal, sepsis
Volume 3 Issue I - 2017

\section{Nupur Hooja, Manharan Singh Netam, Lata Rajoria, Premlata Mital, Manisha Kala, Avantika Sharma}

Department of Obstetrics and Gynecology, S.M.S. Medical College, India

\author{
Correspondence: Nupur Hooja, Professor, Department \\ of Obstetrics and Gynecology, S.M.S. Medical College \& \\ Hospital, A-29, Lal Bahadur Nagar, Girdhar Marg, Malviya Nagar, \\ Jaipur-302017, Rajasthan, India, Tel 09828025302. \\ Email nupurhooja@gmail.com
}

Received: May 21, 2017| Published: November 15, 2017

\section{Introduction}

Maternal mortality is used as a measure of quality of health care in a community. India still has a high maternal mortality rate of 167 per 100000 live births and those who survive suffer from severe maternal morbidity. ${ }^{1}$ Puerperal sepsis despite being preventable is one of the leading cause of maternal mortality and morbidity. In India about 15\% maternal mortality are caused by puerperal sepsis. ${ }^{2}$ Factors leading to puerperal sepsis are varied and may differ in different regions and type of medical care received during delivery and thereafter. The objective of the study was to analyze the factors related to labour in women who develop sepsis in the puerperium so that focus can be made to avoid these factors and decrease the sepsis rate and thus maternal mortality and morbidity.

\section{Methods}

This observational hospital based study was done in a tertiary hospital from April 2016 to March 2017. Expecting 34\% prevalence of puerperal sepsis, among all postpartum complications according to Shamshad et al. ${ }^{3}$ accepting allowable error $20 \%$ and $95 \%$ confidence limit, sample size calculated was 195 postpartum admissions. Women with postpartum complications were analyzed and those in whom two or more of the following present (WHO criteria for puerperal sepsis $)^{4}$ were included in the study -pelvic pain, temperature $38.5^{\circ} \mathrm{C} / 101.3^{\circ} \mathrm{F}$ or higher on any occasion, abnormal vaginal discharge, abnormal smell / foul odour of discharge, delay in the rate of reduction of the size of uterus. $\left(<2 \mathrm{~cm} /\right.$ day during first 8 day). ${ }^{3}$ The study included all women with postpartum sepsis who delivered after 24 weeks of gestation either in the centre or referred from elsewhere due to complications. Selected women were carefully evaluated and managed accordingly.

All data thus collected was entered in excel sheet and was subjected for statistical analysis. Continuous variable were summarized as mean and standard deviation whereas nominal/categorical variables as proportion. Chi square test was used for nominal/categorical variable. $\mathrm{P}$ value $<0.05$ was taken as significant. MEDCALC 14.0.0 version software was used for all statistical test.

\section{Results and discussion}

One target under Sustainable Development $\mathrm{Goal}^{3,5}$ is to reduce the global maternal mortality ratio to less than 70per 100000 births, with no country having a maternal mortality rate of more than twice the global average. Since puerperal infections are one of the leading causes of maternal morbidity and mortality, our focus is now directed at reducing these. This study was undertaken to carry out an analysis of sepsis in the postpartum period to study the factors related to labour leading to infection.

Of the total 195 women with postpartum complications, there were 60 women with puerperal sepsis. Mean age as $25.02+4$.66years. Most of the women belonged to urban area and belonged to lower socio economic status. Most of the women were illiterate and mean parity was $1.75+1.02$.

Most of the women (81.7\%) had institutional deliveries.41.67\% women who developed sepsis had delivered in our hospital. Since the place of study was a tertiary care hospital, the number of unbooked cases, referred cases was high thus contributing to the high incidence of puerperal sepsis in those delivered at the centre.18.33\% had delivered at home and were later admitted with signs and symptoms of puerperal sepsis (Table 1).

The incidence in our study is in contrast to the study of Bako B et al. ${ }^{6}$ where $59.1 \%$ of cases delivered at home while Shamshad et al. ${ }^{3}$ found home deliveries in $73.90 \%$. Unclean delivery practices are the likely factors for the development of sepsis in home deliveries. 
Incidence is likely to be higher in facilities as a result of referred infected cases and nosocomial factors of the women with sepsis who delivered in our hospital, $71.67 \%$ were unbooked. The booking status was according to the presence of their antenatal card. These women had the concept of an antenatal card to be made so that they could be admitted in an emergency. Thus they had only single visit and no further antenatal visits. The women even today did not understand the importance of regular antenatal checkups. In the study of Bako B et al. ${ }^{6}$ and Chandra Madhudas et al. ${ }^{7} 88 \%$ and $90.86 \%$ women were unbooked. In the study of Razia MA et al. ${ }^{8}$ majority of women did not receive any level of care, only $9.8 \%$ had level 3 care.

Table I Place of Delivery of the Women with Puerperal Sepsis

\begin{tabular}{llll}
\hline Place of delivery & & No. $\mathbf{n = 6 0}$ & $\%$ \\
\hline Home Delivery & & II & 18.33 \\
& Private Hospital & 12 & 20 \\
\multirow{3}{*}{ Institutional Delivery } & PHC & 4 & 6.67 \\
& CHC & 8 & 13.33 \\
& Tertiary Center & 25 & 41.67 \\
\hline
\end{tabular}

Fifty three percent women had spontaneous vaginal delivery. $11.67 \%$ had instrumental delivery (forceps and ventouse) (Table 2). It is suggested that other factors other than mode of delivery like duration of labour and or rupture of membranes have a more influential role.

Table 2 Mode of Delivery of Women with Puerperal Sepsis

\begin{tabular}{lll}
\hline Mode of delivery & No. & $\%$ \\
\hline Spontaneous Vaginal Delivery & 32 & 53.33 \\
Instrumental Delivery & 7 & 11.67 \\
Cesarean Section & 21 & 35 \\
\hline
\end{tabular}

In the study of Razia MA et al. ${ }^{8}$ patients who had vaginal delivery were $93.4 \%$. Bako B et al. ${ }^{6}$ also reported that the major risk factor for developing puerperal sepsis was perineal trauma. But according to Kankuri E et al. ${ }^{9}$ postpartum sepsis was 3.2 times more likely to occur after caesarean section than after vaginal delivery. Chaim $\mathrm{W}$ et al. ${ }^{10}$ found the prevalence of postpartum endometritis after cesarean section was $2.63 \%$.

$80.01 \%$ of the women had preterm delivery. Thirty three percent cases were less than 34 weeks gestational age. In the study of Kankuri E et al. ${ }^{9}$ also preterm deliveries were associated with a 2.7 -fold risk for postpartum sepsis as compared to term deliveries (Table 3).

Table 3 Gestational Age of Women with Puerperal Sepsis

\begin{tabular}{lll}
\hline Gestational age(in wks) & No. & $\%$ \\
\hline$<26$ & 3 & 5 \\
$26-29$ & 7 & 11.66 \\
$30-33$ & 10 & 16.67 \\
$34-37$ & 28 & 46.67 \\
$>37$ & 12 & 20 \\
\hline
\end{tabular}

Mean $\pm S D=34.78 \pm 4.82$ wks

Puerperal sepsis was graded depending on the severity. Grade I - infection localized to the uterus, Grade II - infection spreading to pelvis and abdomen without signs of generalized sepsis, grade III - septicemia with clinical evidence of infection -fever, hypothermia, tachycardia, tachypnea and evidence of inadequate organ perfusion. Grade IV - patients with septic shock. ${ }^{11}$

Grade I infection was seen in 58.33 of the women. In our study, infection was mostly confined to uterus because treatment to control the infection was initiated as soon as the patient developed symptoms and or signs of infection. Grade IV was seen in $6.67 \%$ women. Severity of infection was higher in the study by Das Vinita et al. ${ }^{12}$ who found that grade I infection was seen in $40.2 \%$, while grade II $30.3 \%$, grade III infection in $12.3 \%$, while grade IV infection which denoted patients with septic shock and septicemia was seen in $17.2 \%$ cases.

Prolonged labour $>24$ hours was observed in $73 \%$ women. 10 of the 12 women with grade III and IV infection had duration of labour $>24$ hours. All women with grade IV infection had duration of labour $>24$ hours. $\mathrm{P}<0.05$ (Table 4).

Table 4 Correlation of Grade of Infection with Duration of Labour

\begin{tabular}{|c|c|c|c|c|c|}
\hline \multirow{3}{*}{$\begin{array}{l}\text { Grade of } \\
\text { puerperal } \\
\text { sepsis }\end{array}$} & \multicolumn{5}{|c|}{ Duration of labour in hours } \\
\hline & $<12$ & $12-24$ & $24-36$ & $>36$ & \multirow{2}{*}{ Total } \\
\hline & $n=13$ & $n=13$ & $n=23$ & $n=11$ & \\
\hline Grade - I & 10 & 8 & 13 & 4 & 35 \\
\hline Grade - II & 3 & 3 & 4 & 3 & 13 \\
\hline Grade - III & 0 & 2 & 4 & 2 & 8 \\
\hline Grade - IV & 0 & 0 & 2 & 2 & 4 \\
\hline
\end{tabular}

$87.5 \%$ women with grade III and IV infection were primipara. They were also the women who were referred from elsewhere. Their records showed they had trials in various hands before being referred to the health facility.

Of the 60 women of puerperal sepsis, $70.0 \%$ had prolonged rupture of membrane. All women with grade IV of infection had duration of rupture of membrane $>24$ hours. 11 of the 12 women with grade III and IV infection had rupture membranes for more than 24hours. $\mathrm{P}<.05$ (Table 5). Hence implementation of appropriate antibiotic in women with prolonged rupture of membranes should be encouraged to reduce puerperal sepsis.

Table 5 Correlation of Grade of Infection with Duration of Rupture of Membrane

\begin{tabular}{|c|c|c|c|c|c|}
\hline \multirow{3}{*}{$\begin{array}{l}\text { Grade of } \\
\text { puerperal } \\
\text { sepsis }\end{array}$} & \multicolumn{5}{|c|}{ Duration of labour in hours } \\
\hline & $<12$ & $12-24$ & $24-36$ & $>36$ & \multirow{2}{*}{ Total } \\
\hline & $n=8$ & $n=10$ & $n=22$ & $n=20$ & \\
\hline Grade - I & 6 & 5 & 14 & 10 & 35 \\
\hline Grade - II & 2 & 4 & 2 & 5 & 13 \\
\hline Grade - III & 0 & I & 4 & 3 & 8 \\
\hline Grade - IV & 0 & 0 & 2 & 2 & 4 \\
\hline
\end{tabular}

Similar to our study, Dare FO et al. ${ }^{13}$ Shamshad et al. ${ }^{3}$ and Chandra Madhudas et al. ${ }^{7}$ found association between puerperal infection and prolonged labour and premature rupture of membranes however they did not correlate it with the grade of infection as was done in our study. However, Bako B et al. ${ }^{6}$ reported that major risk factors for developing puerperal sepsis as un booked status in $88.0 \%$ and home delivery in $59.1 \%$. 


\section{Conclusion}

Puerperal sepsis is a public health problem and contributes significantly to maternal morbidity and mortality. Puerperal sepsis was observed more in preterm births. Severity was more in women with prolonged labor and prolonged rupture of membrane. Majority of the predisposing and causative factors are preventable. Appropriate antiseptic measures and monitoring are required throughout labour. Antimicrobial sensitivity should be done of all women with prolonged labor or prolonged rupture of membranes.

\section{Acknowledgements}

None.

\section{Conflict of interest or Financial interest}

No financial interest or any conflict of interest exists.

\section{References}

1. World Health Statistics. Health Related Millennium Development Goals, Part-I. 2011:26.

2. Park K. Parks Textbook of Preventive and Social medicine. 18th ed. Health Programmes in India. 2005:414-417.

3. Shamshad, Shamsher S, Rauf B. Puerperal sepsis--still a major threat for parturient. J Ayub Med Coll Abbottabad. 2010;22(3):18-21.

4. WHO. The Prevention and Management of Puerperal Infections Report of a Technical Working Group. WHO Division of Family Health, Geneva; 2008:20-22.
5. www.undp.org/content/undp/en/home/sustainable-development-goals. html

6. Bako B, Audu BM, Lawan ZM, et al. Risk factors and microbial isolates of puerperal sepsis at the University of Maiduguri Teaching Hospital, Maiduguri, North-eastern Nigeria. Arch Gynecol Obstet. 2012;285(4):913-917.

7. Chandra Madhudas, Farkhunda Khurshid. Maternal Morbidity and Mortality Associated with Puerperal Sepsis. JLUMHS. 2011;10:3.

8. Razia MA, Naushaba R, Yasmeen Q, et al. Puerperal Sepsis : An Outcome of Suboptimal Obstetric Care. JLUMHS. 2009;8(1):4.

9. Kankuri E, Kurki T, Carlson P, et al. Incidence, treatment and outcome of peripartum sepsis. Acta Obstet Gynecol Scand. 2003;82(8):730-735.

10. Chaim W, Bashiri A, Bar-David J, et al. Prevalence and clinical significance of postpartum endometritis and wound infection. Infect Dis Obstet Gynecol. 2000;8(2):77-82.

11. Sreelakshmi U, Thejaswini J, Bharathi T. The Outcome of Septic Abortion: A Tertiary Care Hospital Experience. J Obstet Gynecol India. 2014;64(4):265-269.

12. Das V, Agarwal A, Mishra A, et al. Septic abortion. J Obstet Gynecol India. 2006;56(3):236-239.

13. Dare FO, Bako AU, Ezechi OC. Puerperal sepsis: a preventable post-partum complication. Tropical Doctor. 1998;28(2):92-95. 